See Article page 1448.

\section{Commentary: To boldy go}

\section{David J. Barron, FRCS(CT)}

Multiple peripheral pulmonary artery stenoses are a challenging set of lesions that have a long history of being managed primarily in the catheter lab. The very fact that these are usually widespread, bilateral, and often deep within the lung tissue seemed to make them ideal for angioplasty technologies, including cutting balloons and even stenting - as they were deemed to be inaccessible to standard surgical approaches. This series of primary surgical repair from Al-Khaldi and colleagues ${ }^{1}$ in this edition of the Journal has added to a potentially disruptive change in what can be offered surgically for this condition. Together with several reports from the Stanford group, this represents a bold and impressive display of what can be achieved with highly skilled and single-minded surgical perseverance. The demonstration that the entire pulmonary vascular tree (out to segmental branches) can be accessed safely and effectively without the need for hypothermia and circulatory arrest is a testament to improved surgical techniques and expertise, including the importance of meticulous dissection and the use of multiple stay sutures and Yasargil clips to control back bleeding. The outcomes from both this series and from Stanford have been outstanding, with dramatic reduction in right ventricular pressures and freedom from reintervention, which ask us to re-think the way we should be approaching these patients.

In the modern era, it is tempting to feel that traditional surgical techniques are plateauing in terms of the range of lesions that can be treated-and that advances are more likely to come through minimally invasive, hybrid, or interventional techniques. It is rare to see that the boundaries of traditional surgery can still be pushed into areas previously

\footnotetext{
From the Department of Cardiovascular Surgery, Hospital for Sick Children, Toronto, Ontario, Canada.

Disclosures: The author reported no conflicts of interest.

The Journal policy requires editors and reviewers to disclose conflicts of interest and to decline handling or reviewing manuscripts for which they may have a conflict of interest. The editors and reviewers of this article have no conflicts of interest.

Received for publication Aug 30, 2021; revisions received Aug 30, 2021; accepted for publication Aug 31, 2021; available ahead of print Sept 6, 2021.

Address for reprints: David J. Barron, FRCS(CT), Department of Cardiovascular Surgery, Hospital for Sick Children, 555 University Ave, Toronto, Ontario M5G 1X8 Canada (E-mail: david.barron@ sickkids.ca).

J Thorac Cardiovasc Surg 2022;163:1458-9

0022-5223/ $\$ 36.00$

Crown Copyright $(2021$ Published by Elsevier Inc. on behalf of The American Association for Thoracic Surgery

https://doi.org/10.1016/j.jtcvs.2021.08.068
}

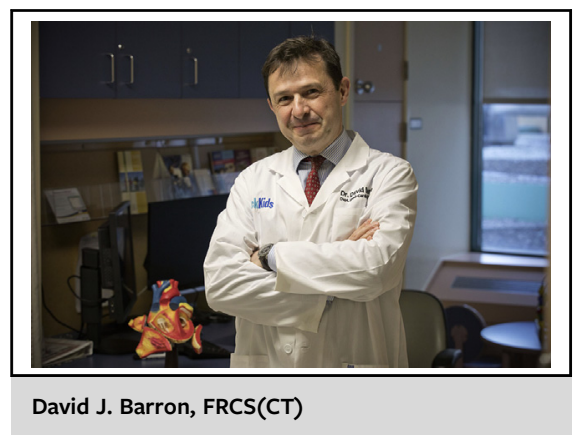

CENTRAL MESSAGE

Surgery for peripheral pulmo-

nary artery stenoses is setting

new standards.

not felt possible, and we should applaud these pioneers of the surgical craft.

These are formidable procedures, with a mean bypass time approaching $61 / 2$ hours and multiple separate patches and angioplasties on no less than a mean of 18 separate stenoses per patient. Despite this, morbidity is low, but not without significant need for postoperative extracorporeal membrane oxygenation $(7.7 \%)$ and a median intensive care unit stay of 6 days-thus, it is important to know that patient selection and timing is justified. A further issue is the preference to use a 2-staged approach with sternotomy and left thoracotomy in cases that require access to the distal left pulmonary arterial tree. This adds significant burden and morbidity to the procedures, and the Stanford group have argued that additional left thoracotomy is not usually necessary.

There remain 2 important unanswered questions: the first is the need for truly comparative groups undergoing catheter interventions so that it can be determined which patients may still benefit from catheter laboratory approaches, which from surgery, and in what sequence. The second is that there are different patterns of disease within this whole cohort-there is not enough data yet to know whether peripheral pulmonary artery stenoses associated with specific syndromes such as Alagille's and William's will do compared with catheter treatment as well as exactly when and where to intervene-especially where the lesions in the latter case tend to actually improve naturally over time. Nevertheless, it is difficult 
to ignore the excellent surgical outcomes in terms of freedom form reintervention-albeit still with relatively short follow-up.

It is welcome to see such ambitious and successful surgical outcomes for this difficult disease, and the next step will be to understand better when to offer this type of extensive surgery over catheter intervention and whether there are certain patient groups, patterns of disease or levels of severity of disease that are better suited to a surgical, catheter-based, or even combined approach.

\section{Reference}

1. Al-Khaldi A, Abuzaid AD, Tamimi O, Alsahari A, Alotay A, Momenah T, et al Late outcomes of surgical reconstruction of peripheral pulmonary arteries. Thorac Cardiovasc Surg. 2022;163:1448-57.e6.
See Article page 1448.

\section{Commentary: Complex pulmonary artery reconstruction (PAR)... on a par with few others}

Frank Hanley, MD

The manuscript by Al-khaldi and colleagues, ${ }^{1}$ published in this edition of the Journal, stands on its own merits. The authors present outstanding outcomes in an extraordinarily challenging patient population. The manuscript, however, represents much more when viewed within the broader arc of the evolution of congenital heart surgery.

Patients requiring pulmonary artery reconstruction (PAR) fall into 3 main categories: arborization abnormalities (eg, major aortopulmonary collaterals); abnormal development with normal arborization (eg, elastin deficiency arteriopathy, such as Williams syndrome and similar phenotypes); and iatrogenic (eg, loss of vasculature after previous surgery or catheter-based intervention). The surgery typically addresses abnormalities at the lobar, segmental, and subsegmental the pulmonary arteries. The techniques used to address these vessels, which have evolved over the past 2-and-a-half decades, are capable of

\footnotetext{
From the Stanford University School of Medicine, Stanford; Children's Heart Center, Stanford Children's Health, Palo Alto; and Division of Congenital Cardiac Surgery, Department of Cardiothoracic Surgery, Stanford University, Stanford, Calif. Disclosures: The author reported no conflicts of interest.

The Journal policy requires editors and reviewers to disclose conflicts of interest and to decline handling or reviewing manuscripts for which they may have a conflict of interest. The editors and reviewers of this article have no conflicts of interest.

Received for publication Aug 16, 2021; revisions received Aug 16, 2021; accepted for publication Aug 17, 2021; available ahead of print Aug 21, 2021

Address for reprints: Frank Hanley, MD, Division of Congenital Cardiac Surgery, Department of Cardiothoracic Surgery, Stanford University, Falk Building, Stanford, CA 94305 (E-mail: fhanley@ stanford.edu).

J Thorac Cardiovasc Surg 2022;163:1459-61

$0022-5223 / \$ 36.00$

Copyright (c) 2021 by The American Association for Thoracic Surgery

https://doi.org/10.1016/j.jtcvs.2021.08.044
}

\section{Check for updates}

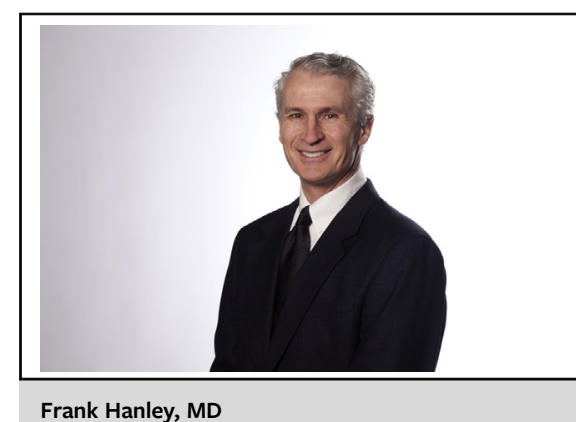

CENTRAL MESSAGE

Complex pulmonary artery

reconstruction represents an

advance thought impossible only

a few years ago.

routinely producing normal or close-to-normal hemodynamics in the pulmonary circulation, ${ }^{2-6}$ an achievement thought impossible by most only a few years ago and by some even today.

Much of the advance in our field over the past 70 years has been driven by evolution of the discipline of reconstructive cardiac surgery. Increasingly complex procedures have been designed to address equally complex anomalies. As specific structural lesions were "conquered" with appropriate procedures, fewer candidates were left available, and naturally these were the most complex anomalies. The impact factor of a new procedure can be defined as the amount of positive change in quality and length of life that the introduction of the procedure imparts on the target patient population. Consider the significant impact factors for several "early" procedures, those for total anomalous pulmonary venous return, ventricular septal defect, or truncus, to name just a few. The Norwood procedure for hypoplastic left heart syndrome was developed in the 1980s, and one could argue that this was the last procedure with an 